\title{
Factors Influencing Compassion Fatigue among Hospice and Palliative Care Unit Nurses
}

\author{
Eun-Ju Cho, R.N., M.S.N. and Hun Ha Cho, R.N., Ph.D.* \\ Palliative Care Unit, Kosin University Gospel Hospital, *Department of Nursing, Kosin University College of Nursing, Busan, Korea
}

Purpose: This descriptive study aimed to explore nursing workplace spirituality, end-oflife care stress, and resilience as factors influencing compassion fatigue among nurses working in hospice and palliative care units. Methods: Data were collected using a self-report questionnaire completed by 146 nurses at 14 hospice and palliative care institutions across South Korea who had worked in a hospice and palliative care institution for at least 6 months and had experience providing end-of-life care. Data were collected from February 25, 2019 to April 12, 2019, and analyzed using SPSS for Windows version 18.0. As appropriate, descriptive statistics, the t-test, analysis of variance, the Scheffé test, Pearson correlation coefficients, and stepwise multiple regression were used. Results: The survey results showed that factors influencing compassion fatigue were resilience, subjective health status, current satisfaction with the hospice ward, and end-of-life care stress. Higher levels of resilience, a subjective health status of "healthy", high levels of current satisfaction with the hospice ward, and lower levels of end-of-life care stress were associated with lower levels of compassion fatigue, explaining $42.9 \%$ of the total variance. Conclusion: The results of this study suggest that resilience is an important factor mitigating compassion fatigue among nurses at hospice and palliative care institutions. Therefore, intervention programs should be developed to reduce compassion fatigue.

Key Words: Hospice and palliative care nursing, Compassion fatigue, Terminal care, Stress, Psychological resilience
Received June 5, 2020

Revised November 18, 2020

Accepted November 25, 2020

\section{Correspondence to}

Hun $\mathrm{Ha}$ Cho

ORCID:

https://orcid.org/0000-0001-9702-0590

E-mail:hhuna@kosin.ac.kr

\section{INTRODUCTION}

\section{Background}

Since 2008, the Ministry of Health and Welfare of the Republic of Korea (hereafter, Korea) has designated and operated specialized hospice and palliative care facilities to improve the quality of life of patients with terminal cancer and their families as part of the national cancer management project, and the rate of use of hospice and palliative care services steadily increased from $7.3 \%$ in 2008 to $22.9 \%$ in 2018 [1]. Nurses working at specialized hospice and palliative care facilities carry out various programs, such as pain and symptom management, end-of-life care, and bereavement care, in cooperation with a multidisciplinary team, during which they experience end-of-life care stress and mental exhaustion, strenuous physical stress, difficulties in nursing depending on the type of cancer, conflicts with the hospice team, and the emotional pain and burden that occur in the nursing setting [2].

Compassion fatigue is a negative phenomenon that occurs when people in occupational caregiving roles are affected mentally, emotionally, and physically by others who have ex- 
perienced high-stress events, by internalizing their pain and suffering while interacting with and helping them in close proximity [3]. The subscales of compassion fatigue include secondary traumatic stress and burnout. In particular, nurses working at specialized hospice and palliative care facilities are among the most sensitive groups for compassion fatigue, as they may internalize a similar level of anger, anxiety, fear, and sadness as felt by their patients and their patients' caregivers while providing care near and at the end of life and managing the symptoms and pain caused by terminal disease [4]. Among nurses working at specialized hospice and palliative care facilities, $78 \%$ experienced a moderate or higher level of compassion fatigue, and approximately $26 \%$ had severe compassion fatigue [5]. Higher levels of secondary traumatic stress and burnout perceived by nurses-corresponding to the subscales of compassion fatigue-were associated with more severe depression, anxiety, and sleep disturbances. Compassion fatigue was found to have a strong influence on increased turnover intention and reduced productivity of the nursing staff. Furthermore, compassion fatigue was confirmed to be an important variable that reduces the quality of nursing services in terms of patient care [6].

Compassion fatigue among nurses working at specialized hospice and palliative care facilities has shown associations with compassion satisfaction [6,7], work stress [8], workplace spirituality in nursing [9], end-of-life care stress [10], and resilience [11].

Nursing workplace spirituality refers to a state in which nurses experience joy and self-realization through a reflection of their inner world and nursing behavior, perceive that the values of their organization and their own are aligned, and have a sense of community through the feeling of being interconnected with colleagues and the process of exchange by giving meaning to nursing in the place where nursing takes place [12]. Higher levels of workplace spirituality among nurses are associated with lower levels of burnout (a subscale of compassion fatigue) and higher job satisfaction [9]. In particular, workplace spirituality has a direct effect on palliative care specialists' care for terminally ill patients, as higher levels of workplace spirituality among palliative care specialists are $\mathrm{ex}^{-}$ pected to lead to more psychological, social, and spiritual care for terminally ill patients [13]. Therefore, to improve the qual- ity of end-of-life care, it is necessary to examine the relationship between workplace spirituality in nursing and compassion fatigue among nurses working at specialized hospice and palliative care facilities.

End-of-life care stress refers to a state where nurses feel work-related physiological, psychological, and social burdens while providing care to patients facing imminent death and their families [14]. Nurses perceive a high level of stress caused by end-of-life care when the workload is heavy, end-oflife care is required during a night shift, administrative procedures are delayed after the patient's death, or they provide care to address the anxiety and sadness of bereaved families [15]. Higher end-of-life care stress is associated with higher burnout (a subscale of compassion fatigue), which in turn negatively affects physical and mental health and professional attitudes, thereby resulting in decreased quality of nursing services, a higher likelihood of nursing errors, and increased turnover intention [10]. Most previous studies on end-of-life care stress examined the relationship between burnout, which is a subscale of compassion fatigue, and end-of-life care stress among nurses working at general hospitals and nursing homes. In contrast, insufficient studies have investigated the effect of end-of-life care stress on compassion fatigue for nurses working at specialized hospice and palliative care facilities that are primarily responsible for end-of-life care. Therefore, it is necessary to investigate the effect of end-of-life care stress on compassion fatigue among nurses working at specialized hospice and palliative care facilities.

Resilience, which literally denotes the ability of a substance to return to its original state, refers to the positive capacity of individuals to rebound from setbacks and adversity and the intrinsic capacity to successfully cope with stress or crisis [16]. Nurses with high resilience have low perceived levels of burnout and stress, which are subscales of compassion fatigue, and have high work adaptability, job satisfaction, and organizational commitment in stressful situations caused by changes in work tasks $[11,17]$. In particular, it was confirmed that resilience affects nurses' performance of end-of-life care, resulting in changes in the quality of nursing care [18]. Therefore, it is necessary to examine the relationship between the resilience of nurses working at specialized hospice and palliative care facilities, whose main task is end-of-life care, and compassion 
fatigue.

Previous studies on compassion fatigue elucidated the relationships of compassion satisfaction [4,7] and work stress [8] with compassion fatigue, mostly among general hospital nurses $[7,8]$ and oncology ward nurses [6]. A few studies have investigated the effects of nursing work spirituality [9], end-of-life care stress [10], and resilience [11] on burnout, a subscale of compassion fatigue, among clinical nurses. However, there is a paucity of research on the factors affecting compassion fatigue among nurses working at specialized hospice palliative care institutions.

Therefore, this study aimed to determine the factors affecting compassion fatigue among nurses working at specialized hospice and palliative care facilities. Furthermore, we sought to provide basic data for the development of interventions to prevent compassion fatigue among nurses working at specialized hospice and palliative care facilities.

\section{Purpose}

The purpose of this study was to identify the factors affecting compassion fatigue among nurses working at specialized hospice and palliative care facilities, and the specific objectives were as follows:

1) To identify the level of nursing workplace spirituality, end-of-life care stress, resilience, and compassion fatigue among participants.

2) To analyze the level of compassion fatigue according to participants' general characteristics.

3) To investigate the relationships between participants' nursing workplace spirituality, end-of-life care stress, resilience, and compassion fatigue.

4) To identify factors that affected participants' compassion fatigue.

\section{METHODS}

\section{Study design}

This descriptive correlational study was conducted to identify the factors affecting compassion fatigue among nurses at specialized hospice and palliative care facilities.

\section{Study participants and data collection}

The participants of this study were nurses working at specialized inpatient hospice and palliative care facilities registered with the Ministry of Health and Welfare. They were selected using convenience sampling from 14 medical institutions nationwide ( 1 in city A, 1 in city An, 4 in city B, 2 in city C, 3 in city D, 1 in city G, 1 in city $S$, and 1 in city U) of the total 85 inpatient hospice and palliative care facilities registered with the Ministry of Health and Welfare. The study participants were those who understood the purpose of the study and consented to voluntary participation, had worked at a specialized hospice and palliative care facility for 6 months or more, had experience of end-of-life care, and completed 60 hours or more of hospice education recognized by the Ministry of Health and Welfare.

The number of required participants was calculated using the $G^{*}$ Power 3.1 program. For multiple regression analysis, with the effect size set to 0.15 , the significance level set at 0.05 , the power set to 0.80 , and 14 predictive factors assumed considering the 11 items on general characteristics and three independent variables, the minimum sample required was 135 people. Considering the potential for dropout, 149 questionnaires were distributed, of which 146 copies, excluding three with insufficient responses, were used for the final analysis.

For data collection, the researchers explained the purpose and process of the research to the head of the relevant medical institutions and obtained consent from the study participants, after which the participants were asked to directly fill out structured, self-reported questionnaires. Data were collected from February 25, 2019, to April 12, 2019, and the data collection method was approved by the Institutional Review Board of K University in B Metropolitan City (IRB number: KU IRB 2018-0103). The questionnaire used for data collection included information on the study purpose, study participation period, procedures and methods, expected risks and benefits, personal data protection, compensation for losses associated with participation in the study, and withdrawal of consent. Written consent was obtained and voluntary participation was guaranteed from an ethical standpoint. 


\section{Research tools}

\section{1) Compassion fatigue}

Compassion fatigue was assessed using a tool described by Kim [19], who adapted Stamm's [3] Professional Quality of Life Scale version 5.0 (ProQOLS: Compassion Satisfaction/ Fatigue Subscale-version 5.0), which is a revised and supplemented version of the original tool developed by Figley [20]. The tool used in this study consists of a total of 20 items and includes two subscales (secondary traumatic stress and burnout). The tool uses a 5-point Likert scale, and higher scores indicate higher levels of compassion fatigue. Kim [19] reported that the total Cronbach's $\alpha$ of the tool was 0.81 , and the values for each subscale were 0.75 for secondary traumatic stress and 0.81 for burnout. In the current study, the total Cronbach' s $\alpha$ was 0.84 , and the values for each subscale were 0.74 for secondary traumatic stress and 0.81 for burnout.

\section{2) Nursing workplace spirituality}

Nursing workplace spirituality was assessed using a measurement tool that Suk and Koh [12] developed for this purpose. The tool has a total of 32 items and is composed of six subscales including interaction with job environment, meaning of nursing, inner self, relationship with colleagues, harmony between workplace and individual, and transcendence through nursing. It uses a 7-point Likert scale, and a higher score indicates higher nursing workplace spirituality. Suk and Koh [12] reported that the total Cronbach's $\alpha$ of the tool was 0.96 , and that for subscales ranged from 0.86 to 0.92 . In the current study, the total Cronbach's $\alpha$ was 0.97 , and that for subscales ranged from 0.88 to 0.94 .

\section{3) End-of-life care stress}

End-of-life care stress was assessed using a measurement tool developed by Lee and Lee [14] for cancer ward nurses. It is a 40-item assessment tool consisting of 7 subscales, including negative attitudes of patient and his/her family members, difficulty of sharing time to the dying patient, burden about bereavement care, overloaded duty, humane relation conflict with dying patient, insufficiency in professional knowledge and skills, and conflict about medical limit. The tool uses a 5-point Likert scale, and a higher score indicates higher end-of-life care stress. Lee and Lee [14] reported the total Cronbach's $\alpha$ was 0.93 and that the Cronbach's $\alpha$ values for each subscale ranged from 0.69 to 0.85 . In the current study, the total Cronbach's $\alpha$ was 0.96 , and the Cronbach's $\alpha$ values for each subscale ranged from 0.79 to 0.92 .

\section{4) Resilience}

Resilience was assessed using the tool proposed by Choi and Seok [22]. They modified the Korean Resilience Quotient-53 (KRQ-53) to use among adults, which Shin et al. [16] had introduced for applying to Korean adolescents by revising and supplementing the original Resilience Quotient Test (RQT), developed by Reivich and Shatte [21]. The tool has a total of 53 items and consists of three subscales: self-regulation skills, interpersonal skills, and positivity. The tool uses a 5-point Likert scale, and higher scores indicate higher resilience. Choi and Seok [22] reported that the overall Cronbach's $\alpha$ was 0.93, and the values for each subscale ranged from 0.79 to 0.86 . In the current study, the total Cronbach's $\alpha$ was 0.92 , and the values for each subscale ranged from 0.82 to 0.87 .

\section{Data analysis}

The data collected in this study were analyzed using SPSS for Windows version 18.0 (SPSS Inc., Chicago, IL, USA) as follows:

1) General characteristics, nursing workplace spirituality, end-of-life care stress, resilience, and compassion fatigue were analyzed by descriptive statistics such as percentage, mean, and standard deviation.

2) Differences in the degree of compassion fatigue by general characteristics of the participants were analyzed by the t-test and analysis of variance, and a post-hoc analysis was performed using the Scheffé test.

3) Relationships between participants' nursing workplace spirituality, end-of-life care stress, resilience, and compassion fatigue were analyzed using Pearson correlation coefficients.

4) Stepwise multiple regression was performed to identify factors affecting compassion fatigue. 


\section{RESULTS}

\section{General characteristics of the participants}

Among the participants, the most common age group was $20 \sim 29$ years $(n=54,37.0 \%)$, the least common age group was 60 years or older $(n=16,11.0 \%)$, and 144 participants (98.6\%) were women. More participants were married $(n=77$, $52.7 \%)$ than unmarried $(n=66,45.2 \%)$. Ninety-two participants (63.0\%) were religious, the majority of participants had a 4 -year bachelor's degree $(n=87,59.6 \%)$, and the smallest number of participants had a graduate degree $(n=24,16.5 \%)$. The largest number of participants had between 6 months and 4 years of work experience ( $n=51,34.9 \%)$, followed by those who had worked for 20 years or more $(n=38,26.0 \%)$. Regarding work experience in the hospice ward, the majority of participants had between 6 months and 2 years of experience $(n=88,60.3 \%)$, followed by those who had worked between 3 and 4 years $(n=31,21.2 \%)$. The number of participants who had not experienced bereavement within the last year was 112 (76.7\%), and most participants provided end-of-life care at least once per week $(n=85,58.2 \%)$, followed by those who

Table 1. General Characteristics of Participants ( $N=146)$.

\begin{tabular}{|c|c|c|c|c|}
\hline Variable & Categories & $\mathrm{n}$ & $\%$ & Mean $\pm S D(\min , \max )$ \\
\hline \multirow[t]{5}{*}{ Age (yr) } & $20 \sim 29$ & 54 & 37.0 & $39.32 \pm 13.67(23,71)$ \\
\hline & 30 39 & 28 & 19.2 & \\
\hline & $40 \sim 49$ & 22 & 15.1 & \\
\hline & $50 \sim 59$ & 26 & 17.8 & \\
\hline & $\geq 60$ & 16 & 11.0 & \\
\hline \multirow[t]{2}{*}{ Gender } & Male & 2 & 1.4 & \\
\hline & Female & 144 & 98.6 & \\
\hline \multirow[t]{3}{*}{ Marital status } & Married & 77 & 52.7 & \\
\hline & Non-married & 66 & 45.2 & \\
\hline & Others & 3 & 2.1 & \\
\hline \multirow[t]{2}{*}{ Religion } & Yes & 92 & 63.0 & \\
\hline & No & 54 & 37.0 & \\
\hline \multirow[t]{3}{*}{ Education level } & Diploma & 35 & 24.0 & \\
\hline & Bachelor's & 87 & 59.6 & \\
\hline & Graduate & 24 & 16.5 & \\
\hline \multirow[t]{4}{*}{ Total career experience at general hospital (yr) } & $0.5 \sim 4$ & 51 & 34.9 & $162.53 \pm 135.56(9,512)$ \\
\hline & $5 \sim 9$ & 24 & 16.4 & \\
\hline & $10 \sim 19$ & 33 & 22.6 & \\
\hline & $\geq 20$ & 38 & 26.0 & \\
\hline \multirow{4}{*}{$\begin{array}{l}\text { Total career experience at hospice and palliative } \\
\text { care institutions (yr) }\end{array}$} & $0.5 \sim 2$ & 88 & 60.3 & $42.07 \pm 40.40(6,252)$ \\
\hline & $3 \sim 4$ & 31 & 21.2 & \\
\hline & $5 \sim 9$ & 16 & 11.0 & \\
\hline & $\geq 10$ & 11 & 7.5 & \\
\hline \multirow[t]{2}{*}{ Bereavement experience within 1 year } & Yes & 34 & 23.3 & \\
\hline & No & 112 & 76.7 & \\
\hline \multirow[t]{3}{*}{ Frequency of experiences of end-of-life care } & Daily & 8 & 5.5 & \\
\hline & At least once a week & 85 & 58.2 & \\
\hline & At least once a month & 53 & 36.3 & \\
\hline \multirow[t]{3}{*}{ Current hospice ward satisfaction } & Satisfaction & 96 & 65.8 & \\
\hline & Neutral & 46 & 31.5 & \\
\hline & Dissatisfaction & 4 & 2.7 & \\
\hline \multirow[t]{3}{*}{ Subjective health } & Healthy & 66 & 45.2 & \\
\hline & Neutral & 51 & 34.9 & \\
\hline & Unhealthy & 29 & 19.9 & \\
\hline
\end{tabular}


provided such care at least once per month ( $n=53,36.3 \%$ ). The majority of participants expressed satisfaction with the current hospice ward ( $n=96,65.8 \%)$, followed by those who were neutral $(n=46,31.5 \%)$. The self-reported health status was healthy for slightly fewer than half of participants $(n=66$, 45.2\%), followed by neutral ( $n=51,34.9 \%)$ (Table 1$)$.

\section{Levels of participants' nursing workplace spirituality, end-of-life care stress, resilience, and compassion fatigue}

The mean score for nursing workplace spirituality was 4.93 \pm 0.91 points (out of 7 points). The mean scores for each sub- scale were as follows: interaction with job environment, 3.81 \pm 1.22 points; meaning of nursing, $5.38 \pm 0.99$ points; inner self, $4.85 \pm 1.24$ points; relationship with colleagues, $5.28 \pm$ 0.93 points; harmony between workplace and individual, 5.15 \pm 1.14 points; and transcendence through nursing, $4.65 \pm 1.18$ points.

The mean score for end-of-life care stress was $3.64 \pm 0.63$ points (out of 5 points). The mean scores for each subscale were as follows: negative attitudes of patient and his/her family members, $3.86 \pm 0.79$ points; difficulty of sharing time to the dying patient, $3.73 \pm 0.71$ points; burden about bereavement care, $3.16 \pm 0.89$ points; overloaded duty, $3.67 \pm 0.73$

Table 2. Nursing Workplace Spirituality, End-of-Life Care Stress, Resilience, and Compassion Fatigue ( $N=146)$.

\begin{tabular}{|c|c|c|c|c|c|}
\hline Variable & Subscale & $\begin{array}{l}\text { Item } \\
\text { number }\end{array}$ & Range & Mean \pm SD of total & Mean \pm SD \\
\hline \multirow[t]{7}{*}{ Nursing workplace spirituality } & Meaning of nursing & 8 & $1 \sim 7$ & $43.00 \pm 7.91$ & $5.38 \pm 0.99$ \\
\hline & Relationship with colleagues & 6 & & $31.66 \pm 5.58$ & $5.28 \pm 0.93$ \\
\hline & Harmony between workplace and individual & 3 & & $15.46 \pm 3.43$ & $5.15 \pm 1.14$ \\
\hline & Inner self & 6 & & $29.12 \pm 7.42$ & $4.85 \pm 1.24$ \\
\hline & Transcendence through nursing & 5 & & $23.26 \pm 5.88$ & $4.65 \pm 1.18$ \\
\hline & Interaction with job environment & 4 & & $15.25 \pm 4.86$ & $3.81 \pm 1.22$ \\
\hline & Total & 32 & & $157.75 \pm 29.17$ & $4.93 \pm 0.91$ \\
\hline \multirow[t]{8}{*}{ End-of-life care stress } & $\begin{array}{l}\text { Negative attitudes of patient and his/her family } \\
\text { members }\end{array}$ & 8 & $1 \sim 5$ & $30.90 \pm 6.28$ & $3.86 \pm 0.79$ \\
\hline & Humane relation conflict with dying patient & 6 & & $22.65 \pm 4.33$ & $3.78 \pm 0.72$ \\
\hline & Difficulty of sharing time to the dying patient & 7 & & $26.13 \pm 4.96$ & $3.73 \pm 0.71$ \\
\hline & Conflict about medical limit & 4 & & $14.84 \pm 3.00$ & $3.71 \pm 0.75$ \\
\hline & Overloaded duty & 5 & & $18.37 \pm 3.66$ & $3.67 \pm 0.73$ \\
\hline & Insufficiency in professional knowledge and skill & 3 & & $10.58 \pm 2.40$ & $3.53 \pm 0.80$ \\
\hline & Burden about bereavement care & 7 & & $22.13 \pm 6.22$ & $3.16 \pm 0.89$ \\
\hline & Total & 40 & & $145.60 \pm 25.16$ & $3.64 \pm 0.63$ \\
\hline \multirow[t]{13}{*}{ Resilience } & Self-regulation & 18 & $1 \sim 5$ & $60.40 \pm 7.58$ & $3.18 \pm 0.32$ \\
\hline & Emotional control & 6 & & $19.03 \pm 3.24$ & $3.38 \pm 0.43$ \\
\hline & Impulse control & 6 & & $20.01 \pm 2.94$ & $3.11 \pm 0.46$ \\
\hline & Cause analysis & 6 & & $21.36 \pm 2.94$ & $3.06 \pm 0.40$ \\
\hline & Positivity & 17 & & $60.60 \pm 8.25$ & $3.14 \pm 0.34$ \\
\hline & Satisfaction with life & 6 & & $19.97 \pm 4.11$ & $3.33 \pm 0.68$ \\
\hline & Ego optimism & 6 & & $20.75 \pm 3.00$ & $3.28 \pm 0.38$ \\
\hline & A grateful attitude & 5 & & $19.87 \pm 2.96$ & $2.75 \pm 0.39$ \\
\hline & Interpersonal skills & 18 & & $63.64 \pm 7.33$ & $3.01 \pm 0.29$ \\
\hline & Communication & 6 & & $19.09 \pm 2.98$ & $3.08 \pm 0.43$ \\
\hline & Empathy & 6 & & $21.54 \pm 2.63$ & $3.07 \pm 0.37$ \\
\hline & Self-expansion & 6 & & $23.01 \pm 3.38$ & $2.88 \pm 0.34$ \\
\hline & Total & 53 & & $184.64 \pm 19.27$ & $3.11 \pm 0.25$ \\
\hline \multirow[t]{3}{*}{ Compassion fatigue } & Total & 20 & $1 \sim 5$ & $56.07 \pm 8.89$ & $3.09 \pm 0.38$ \\
\hline & Burnout & 10 & & $25.97 \pm 5.33$ & $3.17 \pm 0.36$ \\
\hline & Secondary traumatic stress & 10 & & $30.10 \pm 4.99$ & $3.01 \pm 0.49$ \\
\hline
\end{tabular}


points; humane relation conflict with dying patient, $3.78 \pm 0.72$ points; insufficiency in professional knowledge and skill, 3.53 \pm 0.80 points; and conflict about medical limit, $3.71 \pm 0.75$ points.

The mean score for resilience was $3.11 \pm 0.25$ points (out of 5 points). The mean scores for each subscale were as follows: self-regulation skills, $3.18 \pm 0.32$ points; interpersonal skills, $3.01 \pm 0.29$ points; and positivity, $3.14 \pm 0.34$ points.

The mean score for compassion fatigue was $3.09 \pm 0.38$ points (out of 5 points). The mean score for the subscale of secondary traumatic stress was $3.01 \pm 0.49$ points, while that for burnout was $3.17 \pm 0.36$ points (Table 2).

\section{Differences in the level of compassion fatigue by participants' general characteristics}

The level of compassion fatigue was statistically significantly associated with nurses' age $(\mathrm{F}=3.657, \mathrm{P}=0.007)$, marital status ( $\mathrm{F}=4.892, \mathrm{P}=0.009)$, religion $(\mathrm{F}=2.667, \mathrm{P}=0.009)$, work experience $(\mathrm{F}=2.776, \mathrm{P}=0.044)$, experience of bereavement within the last 1 year $(\mathrm{F}=2.170, \mathrm{P}=0.032)$, satisfaction with the current hospice ward $(\mathrm{F}=18.539, \mathrm{P}<0.001)$, frequency of end-oflife care experience $(\mathrm{F}=3.595, \mathrm{P}=0.030)$, and subjective health

Table 3. Compassion Fatigue by General Characteristics of Participants ( $N=146)$.

\begin{tabular}{|c|c|c|c|c|c|c|}
\hline Variable & Categories & Mean $\pm S D$ & tor $F$ & $P$ & Scheffé & $r(P) *$ \\
\hline \multirow[t]{5}{*}{ Age (yr) } & $20 \sim 29$ & $3.09 \pm 0.39$ & 3.657 & 0.007 & - & $-0.284(0.001)$ \\
\hline & 30 39 & $3.08 \pm 0.41$ & & & & \\
\hline & $40 \sim 49$ & $3.19 \pm 0.35$ & & & & \\
\hline & 50 59 & $3.11 \pm 0.39$ & & & & \\
\hline & $60 \leq$ & $2.94 \pm 0.26$ & & & & \\
\hline \multirow[t]{2}{*}{ Gender } & Male & $2.85 \pm 0.64$ & 0.384 & 0.766 & & \\
\hline & Female & $3.09 \pm 0.38$ & & & & \\
\hline \multirow[t]{3}{*}{ Marital status } & Married $^{\mathrm{a}}$ & $3.09 \pm 0.38$ & 4.892 & 0.009 & $b>a, c$ & \\
\hline & Non-married ${ }^{b}$ & $3.09 \pm 0.38$ & & & & \\
\hline & Others ${ }^{c}$ & $2.85 \pm 0.31$ & & & & \\
\hline \multirow[t]{2}{*}{ Religion } & Yes & $3.08 \pm 0.38$ & 2.667 & 0.009 & & \\
\hline & No & $3.10 \pm 0.39$ & & & & \\
\hline \multirow[t]{3}{*}{ Education level } & Diploma & $3.00 \pm 0.39$ & 2.136 & 0.122 & & \\
\hline & Bachelor's & $3.11 \pm 0.38$ & & & & \\
\hline & Graduate & $3.14 \pm 0.37$ & & & & \\
\hline \multirow{4}{*}{$\begin{array}{l}\text { Total career experience at } \\
\text { general hospital (yr) }\end{array}$} & $0.5 \sim 4$ & $3.11 \pm 0.43$ & 2.776 & 0.044 & - & $-0.189(0.022)$ \\
\hline & $5 \sim 9$ & $3.07 \pm 0.30$ & & & & \\
\hline & $10 \sim 19$ & $3.05 \pm 0.39$ & & & & \\
\hline & $20 \leq$ & $3.12 \pm 0.35$ & & & & \\
\hline \multirow{4}{*}{$\begin{array}{l}\text { Total career experience at } \\
\text { hospice and palliative care } \\
\text { institutions (yr) }\end{array}$} & $0.5 \sim 2$ & $3.06 \pm 0.40$ & 1.993 & 0.118 & & $-0.162(0.051)$ \\
\hline & $3 \sim 4$ & $3.22 \pm 0.34$ & & & & \\
\hline & $5 \sim 9$ & $3.11 \pm 0.34$ & & & & \\
\hline & $10 \leq$ & $2.98 \pm 0.38$ & & & & \\
\hline \multirow{2}{*}{$\begin{array}{l}\text { Bereavement experience within } \\
1 \text { year }\end{array}$} & Yes & $3.01 \pm 0.36$ & 2.170 & 0.032 & & \\
\hline & No & $3.12 \pm 0.38$ & & & & \\
\hline \multirow{3}{*}{$\begin{array}{l}\text { Frequency of experiencing } \\
\text { end-of-life care }\end{array}$} & Daily $^{a}$ & $2.86 \pm 0.29$ & 3.595 & 0.030 & $c>a, b$ & \\
\hline & At least once a week ${ }^{\mathrm{b}}$ & $3.13 \pm 0.36$ & & & & \\
\hline & At least once a month ${ }^{c}$ & $3.06 \pm 0.42$ & & & & \\
\hline \multirow{3}{*}{$\begin{array}{l}\text { Current hospice ward } \\
\text { satisfaction }\end{array}$} & Satisfaction ${ }^{\mathrm{a}}$ & $3.04 \pm 0.37$ & 18.53 & $<0.001$ & $c>b>a$ & \\
\hline & Neutral $^{b}$ & $3.16 \pm 0.39$ & & & & \\
\hline & Dissatisfaction ${ }^{c}$ & $3.61 \pm 0.19$ & & & & \\
\hline \multirow[t]{3}{*}{ Subjective health } & Healthy ${ }^{a}$ & $3.00 \pm 0.38$ & 15.834 & $<0.001$ & $c>b>a$ & \\
\hline & Neutral ${ }^{b}$ & $3.13 \pm 0.36$ & & & & \\
\hline & Unhealthy ${ }^{c}$ & $3.23 \pm 0.38$ & & & & \\
\hline
\end{tabular}

*Correlation. 
status $(\mathrm{F}=15.834, \mathrm{P}<0.001)$. In the post-hoc analysis, the degree of compassion fatigue was found to be higher in the unmarried group than in the married group, in participants who were not religious group than in those who were religious, in the group without bereavement experience within the last 1 year than in the group with such experience, in participants who were not satisfied with the current hospice ward than in those who reported neutral responses, in those who provided end-of-life care at least once per month than in those who provided end-of-life care every day or at least once per week, and in the unhealthy group than the healthy group based on the subjective health assessment (Table 3).

\section{Relationships between nursing workplace spirituality, end-of-life care stress, resilience, and level of compassion fatigue}

The degree of compassion fatigue was negatively correlated with nursing workplace spirituality $(r=-0.419, \mathrm{P}<0.001)$, positively correlated with end-of-life care stress $(r=0.231$, $\mathrm{P}=0.005)$, and negatively correlated with resilience $(r=-0.564$, $\mathrm{P}<0.001)$. A positive correlation $(\mathrm{r}=0.622, \mathrm{P}<0.001)$ was found between nursing workplace spirituality and resilience. However, there was no significant correlation of end-oflife care stress with nursing workplace spirituality $(r=0.052$, $\mathrm{P}=0.530)$ and resilience $(\mathrm{r}=-0.111, \mathrm{P}=0.182)$ (Table 4).

\section{Factors affecting the level of compassion fatigue}

In order to determine the factors affecting compassion fatigue, the presence or absence of multiple collinearity between each independent variable was identified, and the tolerance value, variation inflation factor (VIF), and Durbin-Watson value were calculated. Tolerance ranged from 0.955 to 0.985 (all above 0.1) and the VIF ranged from 1.015 to 1.047 (all below 10), indicating that there was no problem of multicollinearity between independent variables. The Durbin-Watson test was performed to verify the independence of residuals and yielded a value of 2.009, which was close to 2 ; thus, there was no autocorrelation between the sums of errors of the model, satisfying the assumption of the normality of residuals and equal variance. The obtained regression model was significant $(\mathrm{F}=28.208, \mathrm{P}<0.001)$.

In order to determine the factors influencing the participants' compassion fatigue, stepwise multiple regression analysis was performed on the following general characteristics that were associated with compassion fatigue levels: age, work experience, marital status, religiosity, bereavement experience within the last 1 year, current hospice ward satisfaction, the frequency of end-of-life care experience, subjective health status, nursing workplace spirituality, end-of-life care stress, and resilience. The most explanatory variable for compassion fatigue was

Table 4. Correlations between Nursing Workplace Spirituality, End-of-Life Care Stress, Resilience, and Compassion Fatigue (N=146).

\begin{tabular}{lccc}
\hline \multicolumn{1}{c}{ Variables } & $\begin{array}{c}\text { Compassion fatigue } \\
\mathrm{r}(\mathrm{P})\end{array}$ & $\begin{array}{c}\text { Nursing workplace spirituality } \\
\mathrm{r}(\mathrm{P})\end{array}$ & $\begin{array}{c}\text { End-of-life care stress } \\
r(\mathrm{P})\end{array}$ \\
\hline Nursing workplace spirituality & $-0.419(<0.001)$ & & \\
End-of-life care stress & $0.231(0.005)$ & $0.052(0.530)$ & $-0.111(0.182)$ \\
Resilience & $-0.564(<0.001)$ & $0.622(<0.001)$ & \\
\hline
\end{tabular}

Table 5. Factors Influencing Compassion Fatigue ( $N=146)$.

\begin{tabular}{|c|c|c|c|c|c|c|c|}
\hline Variables & B & SE & $\beta$ & $\mathrm{R}^{2}$ & $\operatorname{Adj} R^{2}$ & $\mathrm{t}$ & $P$ \\
\hline (Constant) & 87.781 & 6.718 & & & & 13.067 & $<0.001$ \\
\hline Resilience & -0.226 & 0.030 & -0.490 & 0.318 & 0.313 & -7.622 & $<0.001$ \\
\hline Subjective health* & 5.223 & 1.411 & 0.235 & 0.380 & 0.372 & 3.701 & $<0.001$ \\
\hline Current hospice ward satisfaction $^{\dagger}$ & 10.084 & 3.480 & 0.186 & 0.416 & 0.404 & 2.898 & 0.004 \\
\hline End-of-life care stress & 0.060 & 0.022 & 0.169 & 0.445 & 0.429 & 2.672 & 0.008 \\
\hline
\end{tabular}

Tolerance=0.955 0.985, VIF=1.015 1.047, Durbin-Watson=2.009, Adj R²=0.429, F=28.208, $P<0.001$.

Dummy variable.

*Subjective health ( $1=$ Unhealthy, $0=$ Healthy, Neutral), ${ }^{\dagger}$ Current hospice ward satisfaction (1 =Dissatisfaction, $0=$ Satisfaction, Neutral). 
resilience $(\beta=-0.490, \mathrm{P}<0.001)$, followed by subjective health status $(\beta=0.235, \mathrm{P}<0.001)$, current hospice ward satisfaction ( $\beta=0.186, P=0.004)$, and end - of - life care stress $(\beta=0.169$, $\mathrm{P}=0.008)$. The total explanatory power of these variables was 42.9\% (Table 5).

\section{DISCUSSION}

This study was conducted to investigate relationships between nursing workplace spirituality, end-of-life care stress, resilience, and compassion fatigue among nurses working at specialized hospice and palliative care facilities and to examine the effects of these variables on compassion fatigue among them, thereby providing basic data for the development of interventions to prevent compassion fatigue among nurses working at specialized hospice and palliative care facilities.

First, regarding work spirituality, end-of-life care stress, resilience, and compassion fatigue among nurses working at specialized hospice and palliative care facilities, the mean score for the level of work spirituality among the nurses at specialized hospice and palliative care facilities was 4.93 points (out of 7 points), which is somewhat higher than the scores of 4.49 points among general hospital nurses reported by Kown and Oh [23], 4.59 points reported by Suk and Koh [12], and 4.13 points among hospital nurses reported by Jin et al. [9]. In the current study, among the subscales of nursing workplace spirituality, "meaning of nursing" had the highest score, followed by "relationship with colleagues" and "harmony between workplace and individual", similar to the findings in the study of Kown and Oh [23] where the score for "relationship with colleagues" was followed by "meaning of nursing" and "harmony between workplace and individual." The category of "meaning of nursing" refers to the state of experiencing the purpose and value of life through nursing by attaching meaning to and taking pride in nursing, while the category of "relationship with colleagues" refers to bonding with colleagues, sharing purpose and meaning, and resolving conflicts, which contribute to growth [12]. Therefore, it can be seen that experiencing the purpose and value of life while offering hospice care, giving meaning to nursing, and growing with their team members were perceived as the most valuable aspects by nurses working at specialized hospice and palliative care facilities.
However, not many studies have investigated the workplace spirituality of nurses working at specialized hospice and palliative care facilities. Thus, it is necessary to verify these results through further studies in the future.

The mean score for the level of stress among end-of-life care nurses at specialized hospice and palliative care facilities was 3.64 points (out of 5 points), which is similar to the score of 3.96 points among cancer ward nurses reported by Kim and Lee [15]. This similarity may be explained by the fact that the recipients of hospice palliative care are mostly latestage cancer patients, comparable to those in oncology wards. In the current study, among the subscales of end-of-life care stress, the highest score was found for "negative attitudes of patient and his/her family members" (3.86 points), whereas Kim and Lee [15] reported that "Overloaded duty" had the highest score (4.17 points). This suggests that there may be some differences in the factors that cause stress in end-oflife care depending on the ward environment, and it is thus necessary to perform additional studies to further verify these differences. In the current study, the highest score was found for stress related to "negative attitudes of patient and his/her family members", which refers to their denial of the condition and imminent death [14]. This may be because it is difficult for nurses to achieve the goal of hospice palliative care when patients and caregivers have negative attitudes toward death, as the goal of such care is to help them have a good death and to improve the quality of their life until death [24]. Therefore, in order to alleviate end-of-life care stress for nurses at specialized hospice and palliative care facilities, it is necessary to improve negative perceptions of death among patients and caregivers before admission to hospice and palliative care facilities by implementing education on preparation for death, which involves providing information on the overall dying process and facilitating reflection on death through writing of advance directives.

The mean score for resilience of nurses at specialized hospice and palliative care facilities was 3.11 points (out of 5 points), which is similar to the scores of 3.30 points among general hospital nurses reported by Lee [25] and 3.29 points among clinical nurses reported by Kwon [26]. Nurses at specialized hospice and palliative care facilities had the highest score for self-regulation skills and the lowest score for interpersonal 
skills among the subscales of resilience. By contrast, in the study of Lee [25], interpersonal skills had the highest score, and self-regulation skills had the lowest. This discrepancy may be attributable to differences in the tasks assigned to each ward, and additional studies comparing nurses at specialized hospice and palliative care facilities and those in other wards are needed to confirm these differences. In the current study, nurses at specialized hospice and palliative care facilities had high scores for self-regulation skills, which refer to the ability to recognize and control emotions by suppressing emotions and impulsive reactions and devising coping strategies with accurate judgement [16]. This may be because self-regulation skills are crucial to effectively carry out the role of nurses in the hospice palliative care team, which involves the holistic coordination of issues related to patient care, such as providing patients and their families with physical and emotional care and education and creating the environment necessary for $\mathrm{pa}^{-}$ tients [24]. Moreover, in the current study, interpersonal skills, a subscale of resilience, were given the lowest score. However, due to the nature of hospice palliative care, interpersonal skills are the most essential for nurses to establish close relationships with patients and their families and resolve conflicts. Therefore, a strategy needs to be developed to improve the interpersonal skills of nurses at specialized hospice and palliative care facilities to improve their resilience.

The mean score for the level of compassion fatigue among nurses at specialized hospice and palliative care facilities was higher in the current study (3.09 out of 5 points) than the mean score of 2.72 points reported for nurses in general hospitals by Kim and Lee [7]. This may be because, unlike general ward nurses, nurses at specialized hospice and palliative care facilities suffer intense compassion fatigue as they empathize with the emotions of terminally ill or dying patients and families while providing physical, mental, social, spiritual, death, and bereavement nursing care [2]. In the current study, the score for burnout was higher than that for secondary traumatic stress among the subscales of compassion fatigue (3.17 points vs. 3.01 points). The government has mandated the operation of psychological and psychological support programs at each institution to manage burnout among hospice and palliative care team members, including nurses [1]; however, there is a paucity of research on the effectiveness of such burnout prevention programs for nurses at specialized hospice and palliative care facilities. Therefore, in order to alleviate compassion fatigue among nurses working at specialized hospice and palliative care facilities, research is needed to develop a program to prevent overall compassion fatigue, including burnout, and to confirm its effectiveness.

Age and work experience were associated with compassion fatigue, and compassion fatigue was higher among nurses who were non-religious or unmarried, had no experience of bereavement within the last year, or provided end-of-life care at least once per month. Similar findings were also presented by Choi [27], who showed that burnout, a subscale of compassion fatigue, in hospice and palliative care nurses was influenced by age, marital status, religion, clinical experience, and a significant number of deaths in the past month. In the current study, considering that $11 \%$ of nurses at specialized hospice and palliative care facilities were aged 60 or older and they had lower compassion fatigue than other age groups, it can be construed that compared to younger counterparts, older nurses with various experiences in their lives had a higher degree of empathy and acceptance of the situations facing dying patients and their families. Therefore, it is necessary to develop a compassion fatigue relief program according to age and to evaluate its effectiveness. Furthermore, we believe that it will be an effective solution to the workforce shortage to develop and apply a clinical adaptation training program to retrain retired nurses and those who are on paid leave as hospice and palliative care specialists. Moreover, it appeared that compassion fatigue increased due to a lack of experience of accepting death as a natural process of life in participants with limited experiences of bereavement or end-of-life care. Therefore, in order to reduce the compassion fatigue among nurses at specialized hospice and palliative care facilities who have not experienced bereavement or provided end-of-life care, a strategy should be developed to help them accept death as a natural process of life through a program providing an indirect experience of death.

A correlation was found between nursing workplace spirituality and compassion fatigue among nurses at specialized hospice and palliative care facilities. However, nursing workplace spirituality was not found to affect compassion fatigue among nurses at specialized hospice and palliative care facilities. Due 
to the lack of studies on the factors of nursing workplace spirituality that influence compassion fatigue among nurses among specialized hospice and palliative care facilities, it is difficult to directly compare these results, but similar findings were reported in a study by Jin et al. [9] where nursing workplace spirituality was not a cause of burnout, a subscale of compassion fatigue, among general hospital nurses. By contrast, the results reported by Kim and Yong [28] are contradictory to the findings observed in our study: although the participants were not nurses, they found that among adult workers aged 20 years or older, workplace spirituality affected burnout, a subscale of compassion fatigue. Therefore, in order to determine whether these conflicting results were due to differences in wards or occupations, further studies should explore the effect of nursing workplace spirituality on compassion fatigue among nurses at specialized hospice and palliative care facilities. In addition, it is our understanding that the conceptual similarity of the subscales of resilience and nursing workplace spirituality contributed to our findings that nursing workplace spirituality was correlated with compassion fatigue, but did not influence it. Specifically, the subscale of interpersonal skills (i.e., rudimentary skills for resilience; understanding others through communication and empathy and understanding themselves in interpersonal relationships) of resilience is similar to the subscale of relationship with colleagues (i.e., having a sense of community, sharing purposes and meaning, and resolving conflicts together for growth) of nursing workplace spirituality, while the subscale of positivity (i.e., having a positive view of their own feelings and strengths and experiencing joy of life and gratitude) of resilience is similar to that of transcendence through nursing (i.e., experiencing a state of transcendence by thoroughly committing themselves to nursing with positive energy and vitality) in nursing workplace spirituality. Therefore, it appears that resilience is a broader concept than nursing workplace spirituality and has a greater effect on compassion fatigue. Therefore, in the future, it will be necessary to confirm the similarity between these two concepts (nursing workplace spirituality and resilience) and conduct additional studies among nurses at specialized hospice and palliative care facilities to confirm the results of the current study.

In this study, the factors affecting the level of compassion fatigue among nurses at specialized hospice and palliative care facilities were resilience, subjective health status, current hospice ward satisfaction, and end-of-life care stress, with an overall explanatory power of $42.9 \%$. Specifically, higher resilience, higher current hospice ward satisfaction, a subjective perception of good health, and lower end-of-life care stress were associated with lower levels of compassion fatigue.

The most robust explanatory factor for compassion fatigue among nurses at specialized hospice and palliative care facilities was resilience. Due to the lack of research on the factors affecting compassion fatigue among nurses at specialized hospice and palliative care facilities, it is difficult to directly compare the results of this study, but resilience was also reported to be the most explanatory factor of burnout, a subscale of compassion fatigue, among clinical nurses in a study of Ryu and Kim [17]. Resilience is not innate, but an acquired ability that can be affected and developed by external interventions through learning or training. It plays an important role in coping with stress. Resilience refers to the intrinsic capacity that allows an individual to demonstrate his or her maintained or improved ability by coping with and overcoming stressful situations [16]. Therefore, in order to alleviate compassion fatigue among nurses at specialized hospice and palliative care facilities, it is necessary to develop and apply a compassion fatigue intervention program including the enhancement of resilience and to confirm its effectiveness.

In this study, besides resilience, subjective health status and hospice ward satisfaction were found to have the strongest influence on compassion fatigue among nurses at specialized hospice and palliative care facilities. It is difficult to make a direct comparison due to the scarcity of research on factors influencing compassion fatigue among nurses at specialized hospice and palliative care facilities, but a similar finding was reported in a study involving intensive care unit nurses [29], in whom subjective health status affected burnout, a subscale of compassion fatigue. Similarly, Choi [27] reported that work satisfaction influenced burnout among hospice ward nurses. Therefore, as part of efforts to alleviate compassion fatigue among nurses at specialized hospice and palliative care facilities, it is necessary to periodically assess the work satisfaction and health status of nurses at specialized hospice and palliative care facilities to identify those at high risk for compassion fatigue and to apply interventions to prevent compassion fatigue, 
as well as developing strategies to improve work satisfaction and health status at the nursing organization level.

In this study, end-of-life care stress was also found to be a factor influencing compassion fatigue among nurses at specialized hospice and palliative care facilities. In a study involving nursing home nurses, Lee and Park [10] also reported that end-of-life care stress influenced burnout, a subscale of compassion fatigue. However, end-of-life care is the major task of nurses at specialized hospice and palliative care facilities. Therefore, we believe that it is vitally necessary to develop practical strategies to prevent end-of-life care stress in order to alleviate compassion fatigue among nurses at specialized hospice and palliative care facilities. In a study of general hospital nurses by Park et al. [30], more positive attitudes toward a graceful death and death with dignity were associated with lower stress related to end-of-life care. Therefore, it is necessary to develop a program to prevent end-of-life care stress, including cultivating a positive attitude toward death and establishing correct perceptions of death, and to verify its effectiveness, in order to reduce end-of-life care stress among nurses at specialized hospice and palliative care facilities.

In addition, it is necessary to understand the characteristics of compassion fatigue among nurses at specialized hospice and palliative care facilities through additional studies on factors affecting compassion fatigue among these nurses. A practical compassion fatigue prevention program should be developed for nurses at specialized hospice and palliative care facilities based on comparative studies on compassion fatigue involving nurses who work at specialized facilities to provide home or outpatient hospice care, as well as inpatient hospice care.

However, the participants of this study were limited to nurses working at only 14 specialized hospice and palliative care facilities of the total of 85 such facilities nationwide, and the hospitals from which the sample participants were recruited varied in size, limiting the generalizability of our findings to the overall group of nurses working at specialized hospice and palliative care facilities.

\section{CONFLICT OF INTEREST}

No potential conflict of interest relevant to this article was reported.

\section{ORCID}

\author{
Eun-Ju Cho, https://orcid.org/0000-0003-4294-5419 \\ Hun Ha Cho, https://orcid.org/0000-0001-9702-0590
}

\section{AUTHOR'S CONTRIBUTIONS}

Conceptualization: EJC, HHC. Data curation: EJC, HHC. Formal analysis: EJC. Funding acquisition: EJC, HHC. Investigation: EJC. Methodology: EJC, HHC. Project administration: EJC, HHC. Resources: EJC, HHC. Software: EJC. Supervision: EJC, HHC. Validation: EJC, HHC. Visualization: EJC, HHC. Writing - original draft: EJC, HHC. Writing review \& editing: EJC, HHC.

\section{SUPPLEMENTARY MATERIALS}

Supplementary materials can be found via https://doi. org/10.14475/jhpc.2021.24.1.13.

\section{REFERENCES}

1. National Cancer Center. Hospice status and statistics [Internet]. Goyang: National Hospice Center; 2020. [cited 2020 Jul 4]. Available from: http://hospice.cancer.go.kr/pain/stat.do? menu_no=634\&brd_mgrno=.

2. Kwon SH, Tae YS, Hong MJ, Choi GH. Hospice palliative nurses' experience of caring for terminal cancer patients. AON 2015;15:264-75.

3. Stamm BH. The concise ProQOL manual [Internet]. 2nd ed. Idaho: The ProQOL.org; 2010 [cited 2020 Mar 26] . Available form: https://programs.caringsafely.org/wp-content/uploads/2018/01/ProQOL_Concise_2ndEd_12-2010.pdf.

4. Slocum-Gori S, Hemsworth D, Chan WW, Carson A, Kazanjian A. Understanding compassion satisfaction, compassion fatigue and burnout: a survey of the hospice palliative care workforce. Palliat Med 2013;27:172-8.

5. Abendroth M, Flanner J. Predicting the risk of compassion fatigue: a study of hospice nurses. J Hosp Palliat Nurs 2006;8:346-56.

6. Cho HJ, Jung MS. Research trends on compassion fatigue in Korea nurses. J Muscle Jt Health 2014;21:255-64. 
7. Kim JI, Lee TW. The influence of nursing practice environment compassion fatigue and compassion satisfaction on burnout among clinical nurses. J Korean Clin Nurs Res 2016;22:109-17.

8. Lee JM, Yom YH. Effects of work stress compassion fatigue and compassion satisfaction on burnout in clinical nurses. JKANA 2013;19:68997.

9. Jin JH, Ju HO, Kim KS, Park YM. Effects of nursing workplace spirituality on job satisfaction burnout and turnover intention among general hospital nurses. J Korean Clin Nurs Res 2017:23:142-50.

10. Lee JH, Park JS. End of life care stress and nursing work environment in geriatric hospitals nurses affect burn out. JKAIS 2017;18:449-58.

11. Kang JS, Lim JY. Effects of clinical nurses' resilience on job stress and burnout. JKCA 2015;15:263-73.

12. Suk JW, Koh MS. Development of nursing workplace spirituality instrument: confirmatory factor analysis. JKANA 2016;22:99-108.

13. Hong YJ, Lim SH. The Impact of Palliative care practitioners' workplace spirituality on caring for terminally ill people. Kor J Fam Soc Work 2017:57:69-98.

14. Lee YO, Lee HY. A study of cancer unit nurses' stress from bereavement support. The 5th International Nursing Conference; 2005 Oct 1921; Seoul, Korea; Seoul: Korean Society of Nursing Science; 2005. p.229.

15. Kim JH, Lee HK. Cancer unit nurses' end-of-life care-related stress understanding and training needs. Korean J Hosp Palliat Care 2012;15:205-11.

16. Shin WY, Kim MK, Kim JH. Developing measures of resilience for Korean adolescents and testing cross convergent and discriminant validity. Studies on Korean Youth 2009;20:105-31.

17. Ryu K, Kim JK. A study on relationships among resilience, stress, burnout and organizational commitment of hospital nurses. JKCA 2016;16:439-50.

18. Jung SY, Kim JH. Influence of positive psychological capital and death awareness on terminal care performance of hematooncology unit nurses. Korean J Hosp Palliat Care 2019;22:77-86.

19. Kim HJ. The relationships among traumatic events, compassion fatigue, burnout and compassion satisfaction on emergency nurses [master' s thesis]. Seoul: Konkuk Univ.; 2010. Korean.

20. Figley CR. Compassion fatigue: psychotherapists' chronic lack of self care. J Clin Psychol 2002;58:1433-41.

21. Reivich K, Shatte A. The resilience factor: 7 essential skills for overcoming life's inevitable obstacles. New York:Broadway;c2002.

22. Choi HJ, Seok EJ. An analysis of child care teachers' resilience and job satisfaction. Korean Journal of Child Care and Education 2013;75:93115.

23. Kown KY, Oh PJ. Effects of nurses' nursing workplace spirituality and self-efficacy on the patient safety management activities. JKANA 2019;25:106-14.

24. Ro YJ, Kang KA, Ko SJ, Gu YM, Gu IH, Kwon SH, et al. Hospice \& palliative care. Seoul:Hyunmoon Publishing Co.;2018.

25. Lee MK. The relationship between nursing workplace spirituality and resilience of clinical nurses [master's thesis]. Busan: Kosin Univ.; 2018. Korean.

26. Kwon YE. A study on emotional labor, resilience and psychological well-being of clinical nurses. JKAIS 2018;19:339-46.

27. Choi YE. Predictors of burnout among hospice nurses [master's thesis]. Daegu: Kyungpook Univ.; 2013. Korean.

28. Kim MJ, Yong HW. The relation between career adaptability and job satisfaction job burnout: mediating effects of workplace spirituality. Korean Journal of Counseling 2016;17:187-204.

29. Kim SR, Jeon MK, Hwang JH, Choi AR, Kim IS, Pyon MK, et al. Multidimensional factors influencing burnout in intensive care unit nurses. J Korean Clin Nurs Res 2017:23:9-19.

30. Park MS, Kim HY, Kim JY. Convergence factors influencing terminal care stress in general hospital nurses. JCIT 2019;9:28-38. 